\title{
XXXII. On a relation between the surface-tension and osmotic pressure of solutions
}

\section{B. Moore M.A.}

To cite this article: B. Moore M.A. (1894) XXXII. On a relation between the surface-tension and osmotic pressure of solutions, Philosophical Magazine Series 5, 38:232, 279-285, DOI: $10.1080 / 14786449408620634$

To link to this article: http://dx.doi.org/10.1080/14786449408620634

曲 Published online: 08 May 2009.

Submit your article to this journal $[\pi$

Џ Article views: 5

Q View related articles $\asymp$ 
much below that which has been found to be safe in these experiments.

In the experiments of Threlfall the sign of the term depending on time was found to be negative. In some of my earlier experiments it appeared to be negative, but this was traced to irregularity in the working of the compensator ; and the effect has always been positive since the Clark cells have been used in the place of Leclanché, vide $\S \mathbf{5}$.

XXXII. On a Relation between the Surface-Tension and Osmotic Pressure of Solutions. By B. Moone, M.A., Exhibition Scholar, Queen's College, Belfast*.

A $\mathrm{T}$ present the canse of asmotic pressure in solutions is A unknown, although the laws regulating it and connecting it with the kindred solution phenomena, viz. the lowering of the freezing-point and of the vapour-pressure, have been well worked out within the last few years.

This paper is an attempt to show that it may be produced by difference in surface-tension acting along the exceedingly fine capillary openings of almost molecular dimensions which place the solution in connexion with its solvent in the pores of the semipermeable wall which separates them.

If two liquids which mix and have a different surfacetension be placed each in one of two wide tubes communicating beneath by a capillary, as shown in the figure, there is a surface over which capillary action will take place, between each liquid and the wall of the tube containing it. Suppose that the surface-tension of the liquid contained in $A$ is the greater, and that the end of the capillary next A is filled with the pure liquid contained in $A$, and the end next $B$ with the

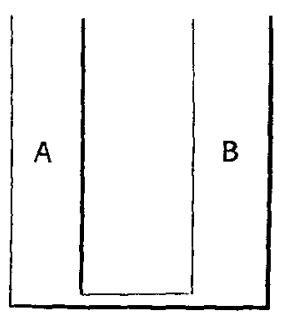
pure liquid contained in $\mathrm{B}$, while between these two points there is a mixture of the two liquids. Then if $\mathrm{T}_{1}$ be the surface-tension of the liquid in $\mathrm{A}$, and $\mathrm{T}_{2}$ that of the liquid in $\mathrm{B}$, the tension along the walls of the capillary will diminish from $\mathrm{T}_{1}$ at the end next $\mathrm{A}$ to $\mathrm{T}_{2}$ at the end next $\mathrm{B}$; and the skin of liquid forming the surface of contact with the walls of the tube will be urged from $B$ towards $A$ by a force of $\left(\mathrm{T}_{1}-\mathrm{T}_{2}\right) 2 \pi r$, where $r$ is the radius of the capillary tube.

$$
\text { * Communicated by Prof. Fitzgerald. }
$$


It might be supposed that the action of this force would cause a rise of level in the tube A. And so it would if the whole cross-section of the capillary were within the range of capillary action; but in a capillary tube, even as fine as one can draw it out, the greater part of the section is still outside the radius of capillary action, and as soon as any difference in pressure is caused by the action of surface-tension, it is effaced by a back flow along the central part of the capillary from A towards B.

However, under the circumstances in which osmotic pressure becomes evident, it is extremely probable that the diameters of the capillaries placing solution and solvent in communication are so exceedingly small that the whole of their cross-section is well within this radius of capillary action. That this is so appears to be proven, not only by the usual mode of formation of such semipermeable walls by causing a precipitate in a finely divided condition in pores already minute, so that the two fluids are only in communication by minute passages between the molecules of this precipitate which must most probably be of molecular dimensions, but also by a simple ealculation based on the assumption that osmotic pressure is due to difference in surface-tension acting as above described.

This calculation leads to an interesting value for the dimensions of the pures and may be stated as follows:-Let ' $\mathrm{T}$ be the difference between the surface-tension of a solution and that of the pure solvent, $P$ the osmotic pressure in this solution, supposed to be due to the action of this difference in surface-tension, and $r$ the radius of a capillary opening placing the solution and the solvent in communication. Then, for a position of equilibrium, the difference in surface-tension acting on the perimeter of the capillary must balance the osmotic pressure acting on its cross-section, and we therefore conclude that the equation $2 \pi r \mathrm{~T}=\pi r^{2} \mathrm{P}$, or $r=\frac{2 \mathrm{~T}}{\mathrm{P}}$, must hold
good.

From this equation, the necessary value which $r$ must have, to account for osmotic pressure in the manner suggested, can easily be calculated.

Rother* gives for the surface-tension of a solution of sodium chloride in water the equation $\alpha=7 \cdot 357+0 \cdot 1566 y$, where $\alpha$ is the surface-tension in milligrams per millimetre, $7: 357$ the surface-tension of water in the same units, and $y$ the number of gram-equivalents of the substance dissolved in 100 equivalents of water, that is in 900 grams. Converting

* W'ied. Ann. xvii. p. 353 (1882). 
the equation into a more convenient system of units, it becomes $\mathrm{T}=72 \cdot 17+1 \cdot 382 n$, where $\mathrm{T}$ is the surface-tension in dynes per centimetre, $72 \cdot 17$ the surface-tension of water expressed in the same units, and $n$ the number of grammolecules dissolved per litre.

Taking $n$ equal to 1 , the equation gives for the difference in surface-tension between a normal solution of sodium chloride and pure water, a value of 1.382 dynes per centimetre.

It is also easy to calculate approximately the osmotic pressure in a normal solution of the same salt, the amount of its dissociation at this concentration being known from Kohlrausch's conductivity determinations. Such a calcnlation gives for the osmotic pressure in such a solution the value of $21 \times 10^{6}$ dynes per square centimetre. Substituting these values in the equation $r=\frac{2 \mathrm{~T}}{\mathrm{P}}$, the value obtained for the radius of the capillary opening is $r=18 \times 10^{-7}$ centimetres.

Now the limits of the radius of capillary action have been determined by various observers and by different methods, and are found to be much greater than this. Thus Plateau's determinations give, for $l$, the radius of capillary attraction, $l>\frac{1}{17000}$ millim. $=6 \times 10^{-6}$ centim. ; and the mean of four determinations of Quincke's for different substances give $l>6^{\circ} 1 \times 10^{-6}$ centimetres.

These results show that the radius of the intercommunicating capillaries necessary to give to the osmotic pressures of solutions the values which they possess by means of capillary action, lies well within the raditus of capillary attraction; so that the whole section of liquid in the capillary would be urged by difference of surface-tension in the direction of the liquid of greater surface-tension, that is from the solvent towards the solution, and thas give rise to a difference of pressure, in other words cause osmotic pressure.

Consider, again, for a moment the relative values of the capillary openings here calculated, and that found as a minimum for the radius of capillary action. The former is $18 \times 10^{-7}$ and the latter $6 \times 10^{-6}$ centimetres; and it follows that, under the given conditions, the capillary opening is smaller than the radius of capillary action, and bence only a portion of the surface-tension will come into action, viz. that acting up to the radius of the capillary instead of to the radius of capillary action. So that the value of $\mathrm{T}$ in the equation $r=\frac{2 \mathrm{~T}}{\mathrm{P}}$ will be diminished, and $r$ will have a still smaller value than that Phil. Mag. S. 5. Vol. 38. No. 232. Sept. 1894 . U 
calculated for it above. T'his alteration in the value of $\mathrm{T}$ will not be so great as the ratios of the two values $6 \times 10^{-6}$ and $18 \times 10^{-7}$ indicate; for the value of the force of molecular attraction varies inversely as some high power of the distance, according to Iaplace inversely as the fifth power of the distance. And it is the portions where the molecular attraction has its smaller values tbat are shut ont as the capillary gradually narrows past the value of $6 \times 10^{-6}$ centimetres.

It follows from these considerations that the capillaries or pores must have a radius of somewhat less than $18 \times 10^{-7}$ centimetres. Now it has been determined by sevoral different. methods that the diameters of molecules lie between $10^{-7}$ and $10^{-8}$ centimetres ; and it is extremely probable that this is the value to which the diameters of these capillary openings in semipermeable walls must approximate. This result is rendered probałble, not only by the reasoning here given, but by the experimental method employed for producing such semipermeable walls, by producing an insoluble precipitate in the minute channels of a porous cell. It secms reasouable to suppose that after snch a process communication takes place only in the intramolecular spaces or meshes of the precipitate, and such meshes must have about the dimensions found for them by the theoretical considerations here given.

If the molecules of the solvent do pass in this manner, in single file as it were, through the immunerable intramolecular spaces of the precipitate forming the semipermeable wall, it follows that the molecular attraction will have a constant maximum value, vi its value just at the surface; and therefore, provided the meshes are so small that the molecules of the solvent can only pass through in siugle file, the osmotic pressure is unaffected by variations in the diameter of the intramolecular meshes. In fict in this condition, instead of a surface-tension acting only for a short distance inward from the perimeter and rapidly falling off in amount, there is a constant molecular attraction acting over the entire cross section and of maximum value; and instead of the equation $2 \pi r^{\mathrm{T}} \mathrm{T}=\pi r^{2} \mathrm{P}$, the equation $\pi r^{2} \tau=\pi r^{2} \mathrm{P}$ or $\tau=\mathrm{P}$, where $\tau$ is the difference in this maximum value for solution and solvent, holds, which shows that the osmotic pressuro really is equal to the difference between the molecular attractions at the surfacelayer of molecules of the solution and of the pure solvent.

With regard to the support furnished by experiment for connecting osmotic pressure with surface-tension, it may be premised that all experiments made on salt or other solutions in water or other solvents have been made with strong solutions, normal and multiples of normal; and it cannot be 
expected that the laws deducible theoretically for the surfacetensions of such solutions can be proven more rigorously than they can in the case of such concentrated solutions for the allied phenomena of solution, such as lowering of vapourpressure and depression of freezing-point.

It will be better to tabulate the results that may be expected to follow in case surface-tension is as closely connected, as here suggested, with osmotic pressure and the other solution phenomena, before discussing them.

(1) The surface-tensions of all solutions, obeying the other solution laws, should be higher than those of the solvents.

(2) For solutions of the same substance in the same solvent, the surface-tension, after correcting for dissociation, should increase directly as the concentration within certain limits of concentration, that is to say, within the same limits as those within which osmotic pressure obeys the gas law.

(3) For solutions of different substances in the same solvent, after correcting for dissociation, the differences in surface-tension between solution and solvent should be the same for equi-molecular solutions of these different substances.

(4) For equi-molecular solutions of either the same substance or different substances in different solvents, after correction for different amounts of dissociation in the different solvents, the differences in surface-tension in each case between the solvent and its solution must be equal, no matter how the surface-tensions of the different solvents may vary.

The only exception to the first law seems to be that of solutions of liquids, themselves possessing surface-tensions of their own, in water and in other liquids; in all such cases the surface-tension lies between the surface-tension of the components. But this is not a real exception: such solutions do not obey the vapour-pressure law either; the vapourpressure of a solution of alcohol in water is not lower, but. higher than that of pure water. On the other hand, all saltsolutions, both in water and other solvents, have a surfacetension higher than that of the solvent.

With regard to the second law, Quincke* found, although working with concentrated solutions, that the increase in surface-tension is very nearly directly proportional to the concentration of the solution, and this result is confirmed by Volkmannt.

Upon the third law the experimental evidence varies. Quincke $\$$ and the earlier experimenters state the law that

* Pogg. Ann. clx. pp. 337, 560.

$\dagger$ Wied. Ann. xvii. p. 353 (1882); xxviii. p. 135 (1886).

$\ddagger$ Vide l. c. 


\section{Surface-Tension and Osmotic Pressure of Solutions.}

the increase in surface-tension is the same for equi-equivalent not equi-normal solutions as the law here described requires; but their results were uncorrected for dissociation, and besides do not agree very closely with the law given by these observers, when so corrected (by dividing the increase in each case by the corresponding value of Arrhenius's coefficient of dissociation $i$ ); they agree almost as closely with one law as the other, and cannot be said to agree with either.

In considering this point of variance, it ought to be remembered that the experiments quoted were carried out with concentrated solutions; for which analogy teaches us, from a consideration of the irregularities shown in depression of freezing-point and vapour-pressure under like conditions, no close agreement can be expected; and besides the quantity to be measured, viz. a small variation in surface-tension, is infinitely more difficult to obtain accurately than the corresponding quantities which are measured in freezing-point: and boiling-point determinations, that is to say, than small differences in temperature.

In the case of dilute solutions these differences would become so small as to be impossible to measure with any approach to accuracy, so that from experimental difficulties this deduction cannot be tested with certainty.

Goldstein *, in a recent paper, states a law which, though expressed differentiy, is practically the same as the third deduction here given, viz.:- In solutions of equal percentage concentration the difference in capillary rise is proportional, after correction for dissociation, to the molecular weight. But as there is no account whatever taken of the densities of the solutions, and the correction for dissociation is made by multiplying the observed difference in capillary rise by $i$, Arrhenius's Coefficient of Dissociation, instead of, as all reasoning and analogy show ought to be done, dividing by that factor, it does not seem to me that much reliance can be placed on the result:

The results given by Quincke for solutions of chlorides in water and alcohol are, when corrected for dissociation, in remarkably close agreement with the fourth deduction stated above.

Quincke'st figures give as the increase in surface-tension of a normal solution of lithium chloride in water, 1.534 dynes per centimetre, and for a normal solution of the same salt in

* Zeitschvift firr physikalische Chemie, v. p. 233 (1890).

+ Pogg. Ann. clx. p. 560. 
alcohol an increase of 968 dyne per centimetre. Correcting the former result for dissociation, the result is a rise corresponding to 953 dyne for a non-dissociated substance in water; and the number 968 for solution in alcohol would undergo but a slight diminution on account of the very small amount of dissociation in alcoholic solution.

Thus it appears that the rise, after this correction has been applied, is almost the same for these two solvents, as it ought to be in accordance with the fourth of the theoretical deductions stated above.

XXXIII. On the Minimum Current audible in the Telephone. $B y$ Lord RAYleigH, Sec.R.S.*

THE estimates which have been put forward of the minimum current perceptible in the Bell telephone vary largely. Mr. Preece gives $6 \times 10^{-13}$ ampere $\dagger$; Prof. Tait, for a current reversed 500 times per second, $2 \times 10^{-12}$ ampere $\Varangle$. De la Rue gives $1 \times 10^{-8}$ ampere, and the same figure is recorded by Brough $\S$ as applicable to the strongest current with which the instrument is worked. Various methods, more or less worthy of confidence, have been employed, but the only experimenter who has described his procedure with detail sufficient to allow of criticism is Prof. Ferraris \|, whose results may be thus expressed :-

$\begin{array}{cccc}\text { Pitch. } & & \text { Frequency. } & \begin{array}{c}\text { Minimum current } \\ \text { in amperes. }\end{array} \\ \mathrm{Do}_{3} & \ldots \ldots \ldots \ldots & 264 & 23 \times 10^{-9} \\ \mathrm{Fa}_{3} & \ldots \ldots \ldots \ldots & 352 & 17 \times 10^{-9} \\ \mathrm{La}_{3} & \ldots \ldots \ldots \ldots & 440 & 10 \times 10^{-9} \\ \mathrm{Do}_{4} & \ldots \ldots \ldots \ldots & 528 & 7 \times 10^{-9} \\ \mathrm{R}_{1} & \ldots \ldots \ldots \ldots & 594 & 5 \times 10^{-9}\end{array}$

The currents were from a make-and-break apparatus, and in each case are reckoned as if only the first periodic term of

* Communicated by the Author, having been read at the Oxford Meeting of the British Association.

$\uparrow$ Brit. Assoc. Report, Manchester, 1887, p. 611.

† Edin. Proc. vol. ix. p. 551 (1878). Prof. Tait speaks of a billion

B.A. units, and, as he kindly informs me, a billion here means $10^{22}$.

\$ Proceedings of the Asiatic Society of Bengal, 1877, p. 255.

II Atti della R, Accad. d. Sci. di Torino, vol. xiii. p. 1024 (1877). 